\title{
Unusual Regiodivergence in Metal-Catalysed Intramolecular Cyclisation of $\boldsymbol{\gamma}$-Allenols
}

\author{
Jannine L. Arbour, Henry S. Rzepa,* Andrew J. P. White and King Kuok (Mimi) Hii* \\ Received (in $X X X, X X X) X$ th $X X X X X X X X X 200 X$, Accepted $X$ th $X X X X X X X X X 200 X$ \\ ${ }_{5}$ First published on the web $X$ th $X X X X X X X X X 200 X$ \\ DOI: 10.1039/b000000x
}

Different $O$-heterocycles can be obtained from a common $\gamma$ allenol precursor by using $\mathrm{Ag}, \mathrm{Zn}$ or Sn catalysts; the results were rationalised by molecular modelling.

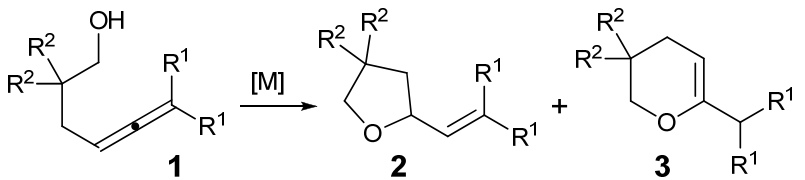

Scheme 15 -exo-trig and 6-exo-dig cyclisation of $\gamma$-allenols.

Intramolecular hydroalkoxylation of $\gamma$-allenols $\mathbf{1}$ can potentially afford 5- or 6-membered O-heterocycles $\mathbf{2}$ or $\mathbf{3}$ via different mechanistic pathways (Scheme 1$):^{1}$ the former (515 exo-trig) cyclisation is more common, and can be obtained using $\mathrm{Pt}^{2 \mathrm{a}}$ or $\mathrm{Au}^{2 \mathrm{~b}}$ catalysts, including enantioselective reactions, ${ }^{3}$ through $\pi$-activation of the $\mathrm{C}=\mathrm{C}$ bond. Conversely, the only known catalytic example ${ }^{4}$ of a 6-endo/exo-dig cyclisation was achieved at $130{ }^{\circ} \mathrm{C}$ using a lanthanide-amide 20 complex, via $\mathrm{C}=\mathrm{C}$ insertion into Ln-O. ${ }^{5}$

In this Communication, we report an unusual observation in the intramolecular cyclisation of $\gamma$-allenols, where the regiochemistry of the process can be altered by using different metal catalysts. ${ }^{6,7}$

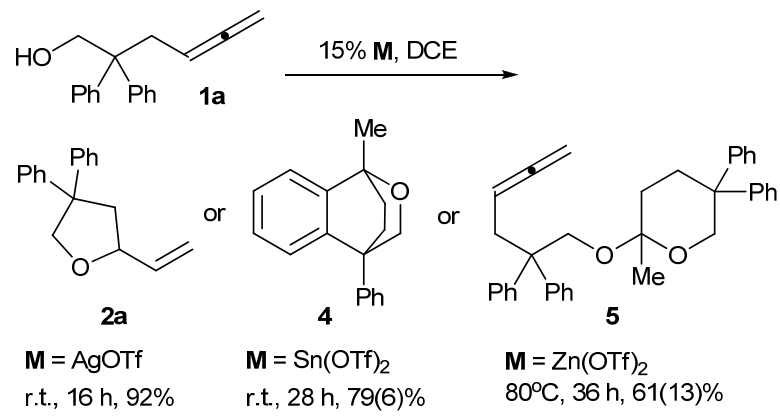

Scheme 2 Metal-catalysed cyclisation of $\mathbf{1 a}$.

The work initiated with the observation that $\gamma$-allenol 1a underwent 5-exo-trig cyclisation in the presence of a catalytic amount of AgOTf to afford 2a. ${ }^{8}$ Subsequent screening of 30 metal triflates led to the serendipitous discovery of two catalysts that effect complementary 6-exo-dig selectivity (Scheme 2): Under virtually identical conditions, $\mathrm{Sn}(\mathrm{OTf})_{2}$ transformed 1a into benzopyran 4 via tandem $\mathrm{C}-\mathrm{O} / \mathrm{C}-\mathrm{C}$ bond formations, while $\mathrm{Zn}(\mathrm{OTf})_{2}$ favoured sequential $\mathrm{C}-\mathrm{O}$ 35 formations to furnish the acetal structure $\mathbf{5}$ at a higher temperature (structures $\mathbf{4}$ and $\mathbf{5}$ were verified by X-ray crystallography, see Supplementary Information). Although small amounts of $\mathbf{2 a}$ were detected in both reaction mixtures (6 and 13\%, respectively), 2a, 4 and 5 did not interconvert 40 when left exposed to the other catalysts, suggesting the operation of competitive and irreversible processes.

The regiodivergence of these catalytic systems was similarly observed with substrates $\mathbf{1 b}$ and 1c (Scheme 3, Table 1): while AgOTf provided tetrahydrofurans $\mathbf{2 b}$ and 2c (entries 451 and 6), corresponding reactions using $\mathrm{Sn}(\mathrm{II})$ and $\mathrm{Zn}(\mathrm{II})$ triflates afforded tetrahydropyran rings as major products at ambient temperature (entries 2, 4 and 8). In the case of $\mathbf{1 b}$, a mixture of double bond isomers $\mathbf{6 a}$ and $\mathbf{6 b}$ was obtained, acetal formation was presumably prohibited for steric reasons. ${ }_{50}$ Rate of the Sn-mediated reaction was attenuated by replacing the diphenyls in 1a with a cyclohexyl group 1c, such that 5membered ring formation became competitive (entry 7). The reaction catalysed by $\mathrm{Zn}(\mathrm{OTf})_{2}$ was also sluggish at room temperature, although the larger ring was still preferred (entry 558 ). At a higher temperature, selectivity for the 6-membered ring product remained unchanged for the system catalysed by $\mathrm{Sn}(\mathrm{OTf})_{2}$ (entries 2 vs 3), while there was a switch in favour of the smaller ring by $\mathrm{Zn}(\mathrm{OTf})_{2}$ (entries 4 vs 5 and 8 vs 9).

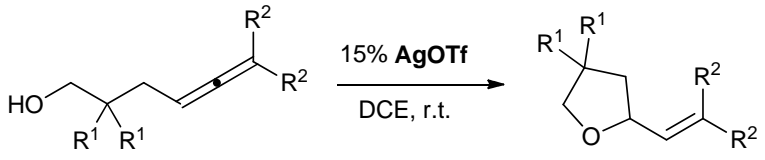

$\mathrm{R}^{1}, \mathrm{R}^{2}=\mathrm{Ph},-\left(\mathrm{CH}_{2}\right)_{5^{-}}(\mathbf{1 b})$

$\mathrm{R}^{1}, \mathrm{R}^{2}=-\left(\mathrm{CH}_{2}\right)_{5}, \mathrm{H}(\mathbf{1 c})$

$\mathrm{R}^{1}, \mathrm{R}^{2}=\mathrm{Ph},-\left(\mathrm{CH}_{2}\right)_{5^{-}}(\mathbf{2 b})$ $R^{1}, R^{2}=-\left(\mathrm{CH}_{2}\right)_{5^{-}}, \mathrm{H}(2 \mathrm{c})$<smiles>C=C(CCC1(c2ccccc2)CCC(C2=CCCCC2)OC1)COC1(c2ccccc2)CCC(OCC(C)C)(c2ccccc2)CC1</smiles>

Scheme 3 5- vs. 6- ring formation.

Brønsted acid catalysis was investigated by addition of 30 mol\% triflic acid to 1a. At room temperature, the formation of 4 was observed in a lower yield $(50 \%$, r.t., $23 \mathrm{~h})$ compared to $\mathrm{Sn}(\mathrm{OTf})_{2} \cdot{ }^{9}$ Likewise, acid-catalysed cyclisation of $\mathbf{1 b}$ led to ${ }_{65} \mathbf{6 a}$ and $\mathbf{6 b}$ (1:6 ratio). However, substrate 1c remained inert over 6 days (r.t.). These observations, accompanied by the switch of selectivity for the 5-exo-trig compound at higher temperatures for the $\mathrm{Sn}$ and $\mathrm{Zn}$ systems, suggest that a $\mathrm{H}^{+}$catalysed process is not likely to be significant. 
Table 1 Cyclisation of $\gamma$-allenols $\mathbf{1 b}$ and $\mathbf{1 c}$ using different catalysts. ${ }^{a}$

\begin{tabular}{|c|c|c|c|c|c|c|}
\hline Entry & Precursor & Catalyst & Product & $\mathrm{t} / \mathrm{h}$ & $\mathrm{T} /{ }^{\circ} \mathrm{C}$ & $\begin{array}{l}\text { Yield }^{b} / \\
\%\end{array}$ \\
\hline 1 & $1 b$ & AgOTf & $2 \mathbf{b}$ & 18 & r.t. & 82 \\
\hline 2 & & $\mathrm{Sn}(\mathrm{OTf})_{2}$ & $\begin{array}{l}\mathbf{6 a}: \mathbf{6 b} \\
(1: 9.25)\end{array}$ & 28 & r.t. & $82(6)$ \\
\hline 3 & & & $\begin{array}{l}\mathbf{6 a}: \mathbf{6 b} \\
(1: 8.3)\end{array}$ & 34 & 50 & $84(2)$ \\
\hline 4 & & $\mathrm{Zn}(\mathrm{OTf})_{2}$ & $\begin{array}{l}\mathbf{6 a}: \mathbf{6 b} \\
(1: 11.5)\end{array}$ & 28 & r.t. & $75(9)$ \\
\hline 5 & & & $\begin{array}{l}\mathbf{6 a}: \mathbf{6 b} \\
(1: 1)\end{array}$ & 34 & 50 & $15(70)$ \\
\hline 6 & 1c & AgOTf & $2 c$ & 12 & r.t. & 76 \\
\hline 7 & & $\mathrm{Sn}(\mathrm{OTf})_{2}$ & 7 & 144 & 35 & $29(40)$ \\
\hline 8 & & $\mathrm{Zn}(\mathrm{OTf})_{2}$ & 7 & 144 & r.t. & $45(9)^{c}$ \\
\hline 9 & & $\mathrm{Zn}(\mathrm{OTf})_{2}$ & 7 & 36 & 50 & $9(52)$ \\
\hline
\end{tabular}

${ }^{a}$ Typical reaction conditions: $\gamma$-allenol $(0.4 \mathrm{mmol})$ in DCE $(0.3 \mathrm{~mL})$, catalyst $(0.06$ mmol., $15 \mathrm{~mol} \%)$. ${ }^{b}$ Isolated yields after column chromatography. Values in parenthesis denote (isolated) yields of the 55 exo-trig compound. ${ }^{c} \mathbf{1 c}$ recovered in $25 \%$ yield.

DFT-based models were employed to provide a rationale for the observed regiodivergence. Using $\gamma$-allenol 1a as substrate, with the counter-ion modelled as triflate $(\mathrm{L}=\mathrm{OTf}$, $\mathrm{X}=\mathrm{SO})$ or trifluoroacetate $(\mathrm{L}=\mathrm{TFA}, \mathrm{X}=\mathrm{C})$, the 5-exo-trig 10 transition state (TS1, Scheme 4) resulting in 2a was tested on group 11 metals $(\mathrm{Cu}, \mathrm{Ag}$ and $\mathrm{Au})$, for which there is reliable experimental data. At the B3LYP/cc-pVDZ level of theory (cc-pVDZ-pp for the metal), the activation free energies $\left(\Delta \mathrm{G}^{\ddagger}\right)$ for TS1 $(\mathrm{L}=\mathrm{TFA})$ were calculated to be 26.7, 18.1 and 12.2

$15 \mathrm{kcal} / \mathrm{mol}$ respectively, commensurate with experimental observations that gold-catalysed reaction occurs at subambient conditions, silver at room temperature, and no reaction was observed with copper under ambient conditions.

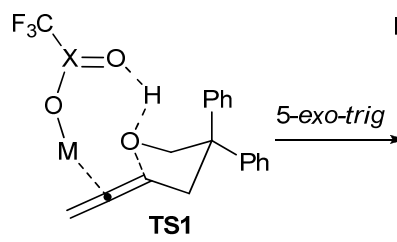

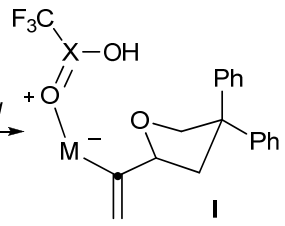

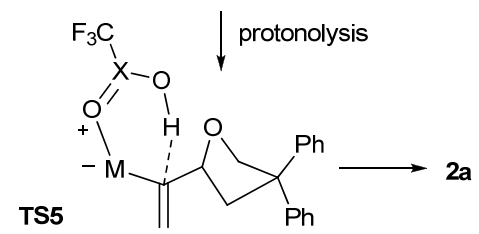

Scheme 4 Proposed pathway for 5-exo-trig cyclisation.

Calculated transition normal modes, illustrated as animations in the Web-enhanced Table $1(\mathrm{M}=\mathrm{Cu}, \mathrm{Ag}, \mathrm{Au})$ and statically (Figure 1), reveal that $\mathrm{C}-\mathrm{O}$ bond formation is assisted by concomitant deprotonation of the $\mathrm{OH}$ group by the 25 adjacent carbonyl of the ligand, the reaction completing with a protonolysis of intermediate I (TS5). Modifying L = OTf to L $=$ TFA is predicted to reduce the barrier by $1.5 \mathrm{kcal} / \mathrm{mol}$, corresponding to a rate increase of ca. 12-fold at ambient temperature. Indeed, this was verified experimentally: 1a 30 underwent complete cyclisation in the presence of $15 \%$ of $\operatorname{Ag}$ (TFA) at room temperature within $2 \mathrm{~h}$ to furnish 2a in $90 \%$ isolated yield (compared to $16 \mathrm{~h}$ by AgOTf, Scheme 2).

Possible mechanistic pathways leading to the formation of 6-membered rings are shown in Scheme 5: TS2 was initially
35 proposed as a pathway to product $\mathbf{4}$, involving electrophilic activation of the allene, followed by aromatic substitution via deprotonation of the Wheland intermediate. Alternatively, the reaction can proceed via TS3, where $\mathrm{C}-\mathrm{O}$ bond formation is followed by protonolysis, resulting in a cyclic enol ether

40 intermediate, which can be trapped by another molecule of 1a to give 5. An alternative to protonolysis is internal proton transfer (II to III, via TS6) followed by aromatic substitution involving $\mathrm{C}=\mathrm{O}+$ as electrophile (TS4), accompanied by synchronous deprotonation of the nascent Wheland 45 intermediate to give 4 . The calculations (Web-enhanced Table $1, \mathrm{M}=\mathrm{Cu}, \mathrm{Ag}, \mathrm{Au}$ ) reveal that TS1 is lower in free energy than TS2 and TS3 for the group 11 metals, in accord with formation of the kinetic product $\mathbf{2 a}$ rather than $\mathbf{4}$ or $\mathbf{5}$.

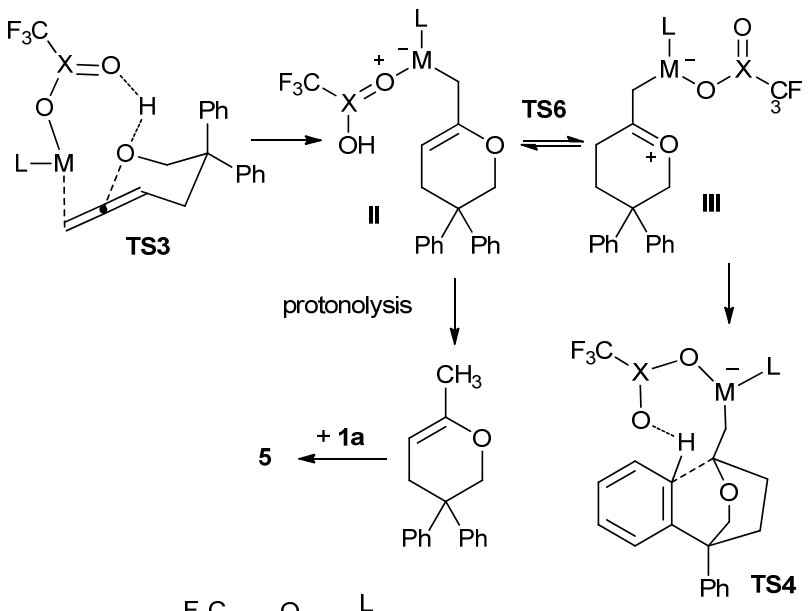<smiles>CCCC1(c2ccccc2)CC(CO)(CO)c2ccccc21</smiles>

Scheme 5 Proposed pathways for 6-exo-dig cyclisations.

Modelling studies for divalent metals are more complex and subtle, with either tetrahedral $(\mathrm{Zn})$ or hemi-directed $(\mathrm{Sn})$ metal coordinated by two bidentate ligands replacing the linear coordination of the group 11 metals, and the possibility 55 of additional coordination to the metal. Annotated geometries for these are set out in Web-enhanced Table 2. In all cases, TS2 is higher in free energy than the other pathways (TS1 and TS3), and can be discounted from further discussion. For $\mathrm{M}=$ $\mathrm{Zn}$, the metal is essentially tetrahedral, achieving this via one ${ }_{60} \mathrm{Zn}-\mathrm{C}$ and three $\mathrm{Zn}-\mathrm{O}$ bonds (from one bidentate and one monodentate ligands). The remaining oxygen from the monodentate ligand acts as the base for proton removal (Figure 1). TS3 $(\mathrm{M}=\mathrm{Zn})$ is now lower in free energy than TS1 (the reverse of that computed for $\mathrm{M}=\mathrm{Ag}$ ), and is assisted 65 by an additional moderate $\mathrm{Zn} . . \mathrm{OH}$ interaction $(\sim 2.5-2.6 \AA)$ not present in TS1. With this metal, the product resulting from TS3 (5) is indeed that observed. Conversely, a different geometry is found for TS3 when $\mathrm{M}=\mathrm{Sn}$. Rather than a tetrahedral, the hemi-directed metal coordination sphere 


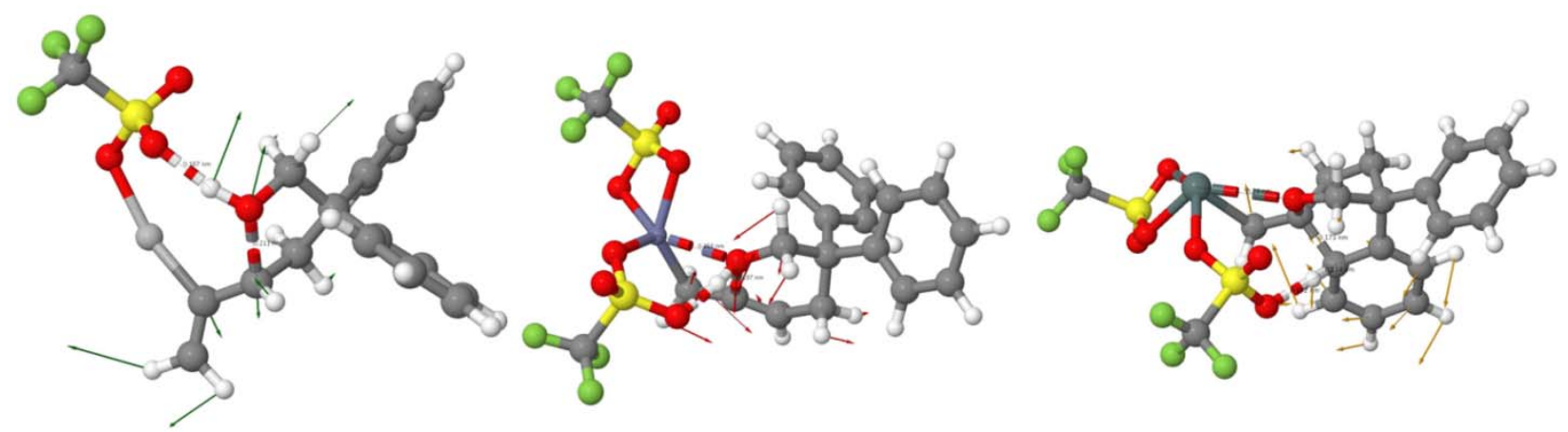

Fig. 1 Calculated normal transition mode for the cyclisation of 1a: TS1 (left, M = Ag), TS3 (middle, M= Zn) and TS4 (right, M=Sn), L= OTf.

comprises one $\mathrm{Sn}-\mathrm{C}$ and two $\mathrm{Sn}-\mathrm{O}$ bonds resulting from monodentate coordination of TFA or OTf, augmented by two 5 much weaker ( 3.0-3.1 $\AA$ ) Sn-O interactions (Web-enhanced Table 2). The product observed with the Sn catalyst is not 2a or 5, but 4 . With the high energy TS2 not providing a route to the observed product, we focused on TS4 (Figure 1) as a possible pathway for $\mathrm{C}-\mathrm{C}$ bond formation. This represents an 10 electrophilic aromatic substitution via a mechanism in which the loss of aromaticity, implied by formation of a discrete Wheland intermediate, is minimised by conflating the C-C bond formation with synchronous deprotonation by an appropriately located oxygen atom from one of the ligands. ${ }^{10}$

${ }_{15}$ Such mechanistic synchronicity has also recently been suggested $^{11}$ for aromatic electrophilic metallations involving C-metal bond formation; our observation extends this mechanistic type to add an example of $\mathrm{C}-\mathrm{C}$ bond formation. The geometry at the $\mathrm{Sn}$ is again notable for a weak $(2.90 \AA)$ $20 \mathrm{Sn}-\mathrm{O}$ interaction augmenting the normal coordination. Nevertheless, the relative energy of TS4 emerged as higher than that of TS1 or TS3. As apparent from Scheme 5, however, TS4 involves a greater degree of charge separation than the other transition states, and indeed the (gas phase) ${ }_{25}$ computed dipole moments are in the region of $12-15 \mathrm{D}$ (compared to $7-10 \mathrm{D}$ for the other transition states). Performing a continuum solvation energy correction for dichloroethane as solvent significantly reduced the relative energy of TS4 ( $\mathrm{L}=\mathrm{OTf}$ ) to below that of the corresponding 30 solvated energies of TS1-TS3. Only one significant discrepancy with experimental observation remains; namely that solvation also reduces the energy of TS4 $(\mathrm{M}=\mathrm{Zn})$ to below that of TS3 (L = OTf). ${ }^{12}$ Nevertheless, these calculations do provide an insight into how the variation in

35 metal coordination can result in differing selectivity by the metals.

To conclude, regioselective cyclisation of $\gamma$-allenols can be directed by Lewis acids via divergent pathways: while Ag catalysis proceeded via a 5-exo-trig pathway, 6-exo-dig 40 cyclisation is favoured by $\mathrm{Sn}$ and $\mathrm{Zn}$ catalysts. Calculations of relative energies of transition states revealed that kinetic control is attained by varying metal geometry and ligand/counterion.

${ }_{45}$ We thank EPSRC and Zambon Advanced Fine Chemicals (ZaCh Systems S.A.) for studentship support.

\section{Notes and references}

Department of Chemistry, Imperial College London, Exhibition Road, 50 South Kensington, London SW7 2AZ, U.K.E-mail: rzepa@imperial.ac.uk, mimi.hii@imperial.ac.uk.

$\dagger$ Electronic Supplementary Information (ESI) available: crystallographic data and cif files for compounds $\mathbf{4}$ and 5 , experimental procedures, and 55 compound characterization (pdf). Coordinates and animated transition state normal modes are provided via Web-enhanced tables. See DOI: $10.1039 / \mathrm{b} 000000 \mathrm{x} /$

1 R. W. Bates and V. Satcharoen, Chem. Soc. Rev., 2002, 31, 12.

602 (a) H. Qian, X. Q. Han and R. A. Widenhoefer, J. Am. Chem. Soc., 2004, 126, 9536; (b) Z. B. Zhang, C. Liu, R. E. Kinder, X. Q. Han, H. Qian and R. A. Widenhoefer, J. Am. Chem. Soc., 2006, 128, 9066.

3 (a) G. L. Hamilton, E. J. Kang, M. Mba and F. D. Toste, Science, 2007, 317, 496; (b) Z. B. Zhang and R. A. Widenhoefer, Angew. Chem. Int. Ed., 2007, 46, 283.

4 Endo-cyclisation of activated allenols was achieved using 1.5 equivalents of t-BuOK: C. Mukai, M. Ohta, H. Yamashita and S. Kitagaki, J. Org. Chem., 2004, 69, 6867.

5 X. H. Yu, S. Seo and T. J. Marks, J. Am. Chem. Soc., 2007, 129, 7244.

6 For our prior work, see: (a) L. A. Adrio and K. K. Hii, Chem. Commun., 2008, 2325; (b) P. H. Phua, S. P. Mathew, A. J. P. White, J. G. de Vries, D. G. Blackmond and K. K. Hii, Chem. Eur. J., 2007, 13, 4602; (c) J. G. Taylor, N. Whittall and K. K. Hii, Org. Lett., 75 2006, 8, 3561; (d) J. G. Taylor, N. Whittall and K. K. Hii, Chem. Commun., 2005, 5103.

7 Regiodivergent (5-endo vs 7-endo-trig) cyclisation of $\gamma$-allenols had been reported, but different protecting groups were deployed on the precursors: B. Alcaide, P. Almendros and T. M. del Campo, Angew. $80 \quad$ Chem. Int. Ed., 2007, 46, 6684.

8 Reactions were reported by using 1.2-2 eq. of $\mathrm{AgNO}_{3}$ : P. Audin, A. Doutheau, L. Ruest and J. Goré, Bull. Soc. Chim. Fr. 1981, 313.

9 After the submission of this manuscript, triflic acid-catalysed reactions of $1 \mathrm{a}$ to $\mathbf{4}$ was reported to proceed in refluxing $\mathrm{CH}_{2} \mathrm{Cl}_{2}(20$ mol\%, $5 \mathrm{~h}, 80 \%$ yield). The crystal structure of $\mathbf{4}$ was also reported: K. Mori, S. Sueoka and T. Akiyama, Chem. Lett., 2009, 38, 628. We are grateful to Prof. Akiyama for bringing the reference to our attention.

10 Retention of ring aromaticity despite having 4-coordination at one of the ring carbons is a known phenomenon, see: (a) R. J. Wehmschulte, B. Twamley and M. A. Khan, Inorg. Chem., 2001, 40, 6004. (b) E. Solari, F. Musso, E. Gallo, C. Floriani, N. Re, A. Chiesi-Villa and C. Rizzoli, Organometallics, 1995, 14, 2265. (c) N. Choi, P. D. Lickiss, M. McPartlin, P. C. Masangane and G. L. Veneziani, Chem. Commun., 2005, 48, 6023.

11 S. I. Gorelsky, D. Lapointe and K. Fagnou, J. Am. Chem. Soc., 2008, 130, 10848 and references cited therein.

12 Advances in computational solvation methodologies will allow solvation potential surfaces to be more effectively explored and the origins of such discrepancies probed; D. M. York and M. Karplus, J. Phys. Chem. A, 1999, 103, 11060-79 as implemented in Gaussian09. 